\title{
PENSAR DESDE EL ABSURDO Y LA INCONSISTENCIA: UNA LECTURA DE EL SOBRINO DE RAMEAU EN POS DE UNA HISTORIA CRÍTICA PARA NUESTRO PRESENTE
}

\author{
JULIO SEOANE PINILLA \\ Universidad de Alcalá
}

\begin{abstract}
RESUMEN: El presente artículo parte de la convicción de que no hay posibilidad de propuestas novedosas y críticas desde una idea de nuestro presente y de nuestra historia como la que habitualmente sostenemos convencidos como estamos de que pasado y presente están unidos de un modo que nuestra razón siempre puede llegar a comprender. De esta manera la posibilidad de cambio o alternativa a nuestro presente siempre queda enmarcada dentro de un cuadro de comprensión coherente y que es muy lejano a la novedad que se puede encontrar en el absurdo y el capricho (ello es la mejor manera de que cualquier propuesta crítica nazca siempre incapaz de promover nuevos modos de concebir nuestro mundo). La obra de Diderot nos presenta la posibilidad de poder conversar incluso con aquello que nos parece absurdo e ininteligible y con ello ofrece una oportunidad a poder concebirnos de manera novedosa e incluso impensada: al contrario que el diálogo, la conversación siempre termina configurándose incluso con momentos absurdos y no completamente comprendidos.
\end{abstract}

PALABRAS CLAVE: Diderot; El sobrino de Rameau; historia crítica.

\section{From the absurdity and inconsistency: Le neveu de Rameau and the chance to envisage a real critical history}

ABSTRACT: This article starts from my conviction that there is no possibility of new thinking and criticism if we begin with our current idea that past and present are united in a way that our reason can always to understand. Thus the possibility of change or alternative to our present always is enclosed within a coherent and closed frame which is alien to the novelty you can find in absurdity and caprice. The work of Diderot gives us the possibility to talk even with what apparently is absurd and unintelligible and thus provides an opportunity to conceive our present in a new and even unexpected way: instead dia-logue conversation always configures itself with a combination of rational and absurd and not fully understood moments.

KEY WORDS: Diderot; Rameau's Nephew; critical history.

Habitualmente solemos explicar nuestro presente por su historia. Ello parece lógico y razonable. Si queremos entender uno de los muchos conflictos que hoy nos asuelan, nuestro primer paso será echar un vistazo a la historia de su conformación para tratar de tener las claves que lo han originado y desde las que se puede solucionar. Mi idea es que proceder tan razonable puede ser pernicioso cuando lo que se desea es encontrar soluciones novedosas a nuestras inquietudes e incomodidades; en la medida en que nuestro presente es hijo del pasado, nuestro presente es el que es y no puede ser otro; en tanto el pasado es quien da razón de nuestro presente, el pasado queda fijado por su mismo dar razón y no puede dar nada que no sea inteligible desde nuestra posición actual. Por ello quisiera leer El sobrino de Rameau tratando 
de encontrar alguna pista para desbordar esta relación entre pasado y presente a fin de lograr una historia que pudiera plantear novedades, diferentes presentes (tanto en lo que se refiere a la construcción de nuestra propia identidad cuanto lo que apunta al mundo social que hoy nos es posible imaginar y soñar); creo que en esta obrita de Diderot la férrea ligazón entre nuestro pasado y nuestro presente - que generalmente hemos bautizado como Historia - se rompe y bajo la incoherencia y el absurdo se abre la posibilidad de poder aprender incluso de allí donde parece que no entendemos nada. La novedad, por propia definición, no puede ser entendida, no puede ser razonablemente encajada en nuestro cuadro de comprensión habitual y por ello solicita un modo de mirar (de mirarnos en nuestro pasado, de mirar a nuestra vida cotidiana) que en primera instancia puede ser calificado de absurdo; Diderot nos plantea que es posible reconocer(nos) en ese absurdo aun sin entenderlo en primera instancia. Por ello creo que nos ayudaría en mucho su ejemplo para tratar de imaginar no ya nuestro mundo presente, sino el futuro que nos cabe.

\section{De nuestra Historia}

\subsection{De su canon}

Es realmente increíble lo sosos que somos a la hora de buscar herramientas de crítica o de encontrar propuestas de un presente distinto. No pocas veces cuando tenemos que hacer tal cosa, una mirada al pasado suele ser habitual, pero es fácil advertir que en la mayor parte de los casos, por mucho que se desee ser crítico con el presente, generalmente se mira a la historia que nuestro presente toma como historia (la cual suele ser $s u$ historia). Es innegable que tiene todos los visos de la sensatez tratar de entendernos mirando el modo en cómo nos hemos construido; como también los tiene la constatación de que tal modo se puede establecer de mil maneras a fin de entender de otras tantas maneras el lugar en el que vivimos. No hay un pasado, eso es algo que nadie va a negar, pero paradójicamente tampoco nadie va a dejar de esbozar una sonrisa cuando alguien le informa sobre su interés en estudiar la filosofía de, pongamos por caso, Felisa Viñas. Sonreímos pues entendemos el loable esfuerzo de recordar a todos los que han hablado alguna vez al tiempo que estamos convencidos de que Felisa Viñas nada tiene que hacer ante figuras tan relevantes para entender nuestro mundo como pudieran ser Kierkegaard o Schopenhauer y menos aún puede aspirar a prestarnos herramientas para construir nuestro futuro del tamaño de las que Hegel o Locke pudieran proporcionarnos. A veces incluso aducimos a nuestro favor que en su día nadie leyó a Felisa Viñas como si los lectores de Kant hubieran sido muy numerosos y no parándonos a reconocer que en su día eran muchos los pensadores muy leídos que hoy nos son muy ajenos. El cual quizás fuera el caso de Felisa Viñas.

Hace ya muchos años, en el proceso de redacción de mi tesis doctoral, atendí a una conferencia en la que se comenzaba exponiendo que nuestra historia del pensamiento es una historia creada no hace mucho desde parámetros neokantianos que priorizaban la teoría del conocimiento. Tenemos, se decía allí, los autores que tenemos (y reunidos según las afinidades con las que quedan reunidos en nuestro mundo intelectual) como bien podríamos haber tenido otros si los criterios de organización de nuestra historia del pensamiento hubieran sido diferentes a los 
gnoseológicos. Lo que más me llamó la atención entonces es que esta afirmación pasó sin mucha controversia, con lo cual yo deduje que nadie ponía en duda que el elenco de antepasados ilustres en el campo de la filosofía a los que es casi deber estudiar era un invento que tenía tantas razones para sostenerse como para enmendarse. Lo curioso es que aun siendo tal un convencimiento más o menos general, a nadie se le ocurre proponer pensadores de altura que no estén ya en nuestro cuadro neokantiano de filósofos de altura (y menos mezclar unas corrientes con otras). Como he dicho no sólo nos resulta extraño que alguien gaste sus esfuerzos en liderar la causa a favor de Felisa Viñas como pensadora de relevancia comparable a Bergson pongo por caso, sino que, además, son pocos los que unirían a Hume con Rousseau y Reid - por poner otro caso- en un estudio serio de la historia del pensamiento moderno.

Esta imposibilidad es todavía más llamativa cuando se elabora una historia de los conceptos, pues no entendiendo estos de escuelas filosóficas — sean estas establecidas desde una particular teoría del conocimiento o desde cualquier otra perspectiva organizativa-, a fin de poder expresarse de modo conveniente nos pueden llevar por el empirismo y el racionalismo amén de por el sentimentalismo literario o el neoclasicismo escultórico y quién sabe por qué pagos más, todos ellos difícilmente localizables en los dominios establecidos en torno a nuestros autores y corrientes filosóficas de relevancia. Y tan sosos solemos ser que raramente se plantea nuestro presente con un pasado tan viajero que sea capaz de recogerse en autores de diferentes escuelas o tradiciones o disciplinas ${ }^{1}$. Estamos convencidos de que la Historia es seria y si viaja no lo hace sin llevar en la mochila algún propósito ý con ánimo de establecer comparaciones y entenderse mejor; de que rara vez sale de paseo con el talante del viajero que gusta de perderse y olvidar el camino inicial que llevaba al comienzo de su marcha. Por eso generalmente consideramos que hay mezclas absurdas y uniones estúpidas y poco le dice a la Historia del pensamiento la reunión de Montaigne con Vauvenargues y Benjamin. Aparte de su calidad circense, con un estudio de semejante guisa no se va a ningún sitio. A ninguna parte en la que podamos estar interesados. Es cierto que nuestra historia del pensamiento puede ser inventada, pero no lo es menos que hay una historia del pensamiento que se puede relatar con un poco de buena voluntad y trabajo riguroso. Una historia que nos mostrará cómo Kant, Hegel o Foucault nos son mucho más cercanos (son más nosotros) que Felisa Viñas. Es indiscutible que aún no hemos llegado a dar con la completud de la Historia, que cada día descubrimos algunos olvidos, pero ello no

1 Por poner un ejemplo personal: cuando se estudia el fundamental concepto de simpatía en Adam Smith es inevitable, aparte de recordar a Hutcheson y a Hume, reunirle con Rousseau y su idea de piedad e, inmediatamente, recordar a Richardson y las dos cumbres de la novela sentimental que son Pamela y Clarissa. Llegados aquí sería muy complicado no ver la relación entre ese sentimentalismo y buena parte del Pragmatismo que se propuso en su día entre James y Dewey — quizás, quién sabe, entre la admiración por el sentimentalismo que inundó Norteamérica en el XIX, quizás debido a la admiración de Peirce por Reid-el cual se expresa de la manera más sentimental en la obra final de Rorty. No es que yo quiera presentar esta reunión de autores como una línea de pensamiento que debiera sustituir a las corrientes que de modo clásico estudiamos, pero sí que es cierto que tal reunión de autores nos puede prestar herramientas para descifrar nuestro presente tan útiles al menos como las clásicas agrupaciones de pensadores que solemos tener en la cabeza. Y es inconcebible cuan pocas de estas «nuevas agrupaciones» solemos ver. 
quita que realmente somos como somos y no estamos perdidos al albur de que a alguien se le ocurra decirnos que nos describimos de mejor manera con Pascal, La Rochefoucauld y Baudrillard y que debiéramos ir preparados para cualquier sorpresa todas las mañanas cuando abrimos los ojos delante del espejo. Estamos convencidos de que hay cosas realmente importantes y lo que somos es una de ellas; y eso no puede cambiar ante cualquier veleidad caprichosa.

\subsection{De su objetividad}

Benjamin apuntó en su momento que la verosimilitud de una narración provenía del hecho de que el narrador la vivía y era parte de la misma²; para nuestra historia eso es síntoma de que el relato no es histórico, no es de fiar, que es un cuento — sin ningún sentido histórico, un poco caprichoso- . Nuestro modelo es el de la tercera persona merced al cual podemos ser nosotros como si fuéramos otro, pero siendo siempre nosotros; esto es, contamos nuestra historia como si fuera personalmente nuestra, pero sabiendo que lo que contamos lo contamos desde una posición ajena a la cotidianeidad de los diferentes sucesos históricos que personalmente nos afectan. Sólo así tenemos la seguridad de que ese que se mira al espejo siempre se verá igual; si tal visión dependiera del capricho sería entonces posible perderse reconociendo cada mañana a alguien diferente. Como antes dije lo que nosotros somos de verdad tiene que ser algo permanente (universal en tanto siempre y en todo lugar nos ha de ser posible reconocernos), lo cual nos permite un ejercicio de empatía (o solidaridad) por el cual podemos reconocer a los demás como otros universales iguales a nosotros que pueden contar la misma historia. ¿Se imagina alguien que cada individuo pudiera contar una historia? Entonces no habría Historia en absoluto y pasaría como aquel que se extraña ante el espejo o que, puesto ante la historia del pensamiento, se pierde estudiando las infinitas Felisas Viñas que pueden hacerse aparecer (según el capricho y la habilidad acrobática del pensamiento). Somos lo que somos porque podemos relatarnos de un modo que va algo más allá de lo que en cada momento somos. Nos relatamos en tercera persona al igual que contamos nuestra vida con los demás en tercera persona; y así obtenemos una historia que sirve para comprendernos con/entre los demás. No estoy diciendo nada extraño: sería absurdo imaginarse siendo y no siendo; tan absurdo como estúpido sería componer sociedad con los demás atentos sólo al capricho y al azar. De absurdo y de capricho es de lo que quiero hablar aquí de la mano del sobrino de Rameau, pero antes me gustaría que quedara claro que la historia en tercera persona permite que no se mezclen intereses ni prejuicios presentes en la explicación que nos muestra cómo somos (en la realización del proyecto agustiniano donde el presente se ve como el fruto de todo el camino previamente andado). La tercera persona se dice generalmente como "cientificidad» u «objetividad», pero es fácil imaginarla diciéndose como «marcha de la historia» o "historia del concepto» o hasta como «naturaleza» que nos hace caminar por donde debemos caminar sin siquiera saberlo nosotros. Al fin y al cabo el mercado que autorregula la marcha del mundo social no es muy distinto al mundo de las virtudes públicas que advienen

\footnotetext{
2 Benjamin, W., El narrador, Madrid, Taurus, 1991.
} 
con los vicios privados o al mundo de la «astucia de la razón», como tampoco lo es al decurso de la «propia» Historia y su racionalidad ínsita.

Frente a la historia que se hace en tercera persona y que tiene todos los avales de la cientificidad y la racionalidad, me gustaría recordar la historia concebida simplemente como maestra de la vida que utiliza otro artificio narrativo (y de comprensión del mundo al que se dirige) diferente al de la tercera persona. Creo que como maestra seguramente trata de explicar también su presente, pero esa explicación la da mirando al alumno y tomando cuidado de él justo en el momento en que comienza a configurar su propia identidad con los relatos que la misma historia proporciona. Por no ser muy abstruso: quiero imaginar una historia que resulta maestra de la vida porque abandona la visión de tercera persona y de alguna manera se hace una con aquel que la escucha, que la atiende y que desea no tanto explicaciones objetivas de su presente, sino ayuda y esperanza para salir de él -o perseverar con mayor gozo-. La historia que se narra del modo en como Benjamin consideraba propio del narrador, se convierte en un cuento vivido y optado por aquellos que deciden atenderla y hacerla suya.

He hablado de historia como maestra de la vida y quizás también valiera hablar de historia como viaje curioso por lugares por donde no hemos estado. Como todo maestro sabe es a través de despertar la curiosidad como se aprende de mejor manera y posiblemente la historia pueda enseñarnos algo (o pueda prestarnos herramientas útiles para nuestra vida) cuando se presenta al curioso que viaja simplemente con el acicate de ver otras cosas, otras maneras de hacer y de vivir. Para imaginar esa otra historia (ligada al gusto del curioso de manera opuesta a cualquier objetividad) me gustaría visitar un modo de dar cuenta de sí y de la vida con los demás que es el que se nos presente en El sobrino de Rameau de Diderot.

\section{La historia ¿UN RELATO DE CUALQUiER COSA?}

\subsection{La falta de nombre. Una historia ¿de qué o quién?}

Se suele decir que El sobrino de Rameau es un libro «raro» dentro de la producción de Diderot ${ }^{3}$. Él mismo no hizo esfuerzo alguno por publicarlo una vez que lo terminó de escribir y no fue hasta su muerte que, encontrado entre sus manuscritos, salió a la luz. Como seguramente se recordará esta obrita es un diálogo entre Yo y Él, siendo el primero la voz de Diderot y el segundo la del sobrino de Rameau. Aunque realmente lo que inmediatamente chirría al leer el libro es que no resulta claro que Yo sea Diderot aunque tradicionalmente así se ha interpretado y nos resultaría muy difícil leerlo si así no fuera. Ciertamente alguien tiene que contar la historia y ese alguien no puede menos que ser el narrador que se llama a sí mismo Yo, pero según pasan las páginas se afianza una sospecha (posiblemente de manera algo estúpida y sin mucha razón): quizás el narrador que cuenta el texto no sea Diderot, sino un

A partir de ahora las citas de El sobrino de Rameau se seguirán inmediatamente, y entre corchetes, del número de página de la edición castellana (Diderot, D., El sobrino de Rameau, Madrid, Cátedra, 1985) seguido del número de página de las Oeuvres Complètes de Diderot (tomo XII, dirigido por H. Coulet, París, Hermann, 1989). 
personaje más que Diderot ha creado que no tiene por qué coincidir con el Diderot que nos cuenta el texto (y a lo mejor ni siquiera con el personaje Yo).

Como fuere, lo cierto es que la lectura tradicional de El sobrino de Rameau suele ser o la que toma las voces de Yo y de Él como dos voces de Diderot (algo así como su Yo consciente y su Yo inconsciente) que él mismo se encarga de acordar u organizar para poder configurar su propia identidad, o la lectura que instituyó Hegel que lee en Él la conciencia desgraciada de la Modernidad que solicita, para no caer en la locura, un paso más, tan sólo un paso más, para recoger su continua reductio absurdum en un discurso racional (y comprensible) ${ }^{4}$. Entre ambas lecturas se tensa el arco de la identidad personal y social que, como vimos, es el arco de la historia pues es difícil dar con un modo de contarme a mí mismo que no sea extensible a la manera de contarme con los demás (y viceversa); y en esa tensión se da cuenta de por qué Felisa Viñas nos dice mucho menos que Hegel, de por qué la historia de nuestra vida, la que adoptamos para contarnos en el mundo se dice con palabras capaces de hacer un discurso coherente y total. Vence Yo y pierde Él, como vence Hegel y pierde Felisa Viñas, y a poco que leamos el texto de Diderot, veremos que ello es lo más natural (si no deseamos caer en la locura). Pero ¿realmente así ha de ser? ¿nos es imposible vivir en un mundo incoherente, deshecho y estúpido? ¿es evidentemente preferible la coherencia, el discurso inteligible en todo momento y, sobre todo, resoluble, capaz de decir la última palabra? Es de reseñar que El sobrino de Rameau termina como empieza, sin que nada se haya resuelto, sin que después de bastantes páginas de conversación se pueda concluir o decir nada en resumidas cuentas: se separan quienes se habían encontrado casualmente y cada quien sigue con su vida. Lo curioso del caso es que Yo no presenta su fastidio por haber perdido tanto tiempo sin haber concluido nada, por haber estado hablando con un payaso que no ha dejado de hacer el tonto y que se va como ha venido; y posiblemente ello sea así porque algo ha aprendido aunque parezca que nada se ha dicho. O posiblemente sea porque tanto Yo como Él son las diferentes voces de una misma persona, Denis Diderot. Que ello sea posible, que alguien sea capaz de reconocer dos voces en sí mismo que no han de ser ni reconciliadas ni subsumida una por otra, ya dice bastante de lo que aquí quiero presentar. Él es tan yo como Yo y parece que el hecho de que hayamos dado en seguir a uno y no a otro (o que hayamos pensado que no podemos caer en la locura y que Yo ha de saber o subsumir o dominar a su "otro yo») es sencillamente un factor "históricamente construido» por decirlo así, algo que no era ni obligado ni, por supuesto, nos ha proporcionado con seguridad el mejor mundo de los posibles. Esto es lo que quiero aquí defender: aunque la interpretación habitual sea la que parte de la evidencia de que nadie puede vivir como el sobrino de Rameau, que nada puede aprenderse ni proponerse desde la continua pantomima y la actuación sinsentido, me da la

\footnotetext{
4 Él está a falta de un paso que lo integre en una verdadera razón universal y tiene su valor, importante valor, sólo en tanto que paso a esa razón. Hegel presentó esta lectura en La fenomenología del espíritu y dedica un apartado, el titulado "La vanidad de la cultura», precisamente a exponer la marcha del espíritu al hilo de esta obrita de Diderot; desde entonces su impronta ha llegado a uniformar buena parte de la crítica de El sobrino de Rameau (un ejemplo paradigmático es la lectura de JAcoues D'HondT en su artículo «Le cynisme de Rameau», Recherches sur Diderot et sur l'Encyclopédie, no 36 (2004), pp. 125-137, aquí pp. 130-132).
} 
impresión de que hoy no nos cabe crítica alguna si no toma en serio a un personaje que con tanta seriedad es idiota.

Pero vayamos por partes. Lo primero a notar: el sobrino de Rameau ni siquiera tiene nombre. La crítica ha llegado a averiguar su verdadero nombre y a conocer que tenía una situación no muy diferente a la que aparece en el relato de Diderot, pero lo cierto es que en el texto no aparece sino como «el sobrino de Rameau», lo cual creo que es relevante ${ }^{5}$. No es alguien, no sé si no es nadie, pero a primera vista no parece el mejor de los lugares para que nuestra historia encuentre herramientas críticas. Sigamos. El sobrino de Rameau a fuer de no ser nadie continuamente imita y se hace otro, nunca aparece como siendo esencialmente nada, sino que siempre es continuamente otro (ya no sólo otro personaje, sino incluso otra «cosa», sea violín, plato o estornudo). El sobrino no sabe hablar sin salir de sí y convertirse en aquel de quien habla o en aquello de lo que habla (es alguien sin "yo» ninguno:¡cómo que es Él!); puesto que no calla, resulta que no podemos saber quién efectivamente es y ello es lo que constituye el leif motif del texto: la continua extrañeza de Diderot ante alguien que no tiene la consistencia para aguantar ningún discurso (ni suyo ni dirigido a él).

De hecho la primera descripción del sobrino de Rameau que Diderot nos ofrece es la de un individuo sin identidad. Un día de una manera, otro de otra, sin tener nunca claro cómo será mañana y (aunque esto no se nos dice) sin saber siquiera qué fue ayer: "vive al día» es decir, sin vínculo de unión entre el ayer y el hoy, sin biografía, sin identidad ${ }^{6}$. Triste y alegre según las circunstancias que nunca domina, siempre dejándose llevar por ellas ( «las malditas circunstancias nos llevan y nos llevan mal» [p. $157-188-$ ]) con lo que al final no es sino una pluma arrojada al viento. Ello es lo que le hace aparecer continuamente como un loco; sin tener un poso que de alguna manera signifique su identidad, el sobrino de Rameau termina diciendo una cosa y su contraria y nunca sabe quién es él mismo más allá de ser quien se expone en una charla casual (¿con Denis Diderot?) y quien se deshace de lo dicho una vez que parte de la charla hacia la Ópera con un «¿no es cierto que sigo siendo yo mismo? ${ }^{7}$. Pero ¿quién es ese que no tiene un yo, que no es un sujeto capaz de sujetar lo que dice, que no tiene identidad? Uno, la verdad, siempre tiene la impresión de que Él está loco (y por eso las interpretaciones de corte conscienteinconsciente vienen muy al caso $^{8}$ ).

\footnotetext{
5 Es cierto: Yo tampoco tiene nombre y aparece solamente como Yo, pero por alguna razón no muy obvia tendemos a considerar que se llama Denis Diderot.

6 «Hoy con la ropa sucia, el pantalón desgarrado, cubierto de andrajos, casi descalzo, anda cabizbajo, se oculta, y uno siente la tentación de llamarle para darle una limosna. Mañana, empolvado, calzado, rizado, bien vestido, lleva la cabeza alta, se exhibe y casi lo tomaríais por un perfecto caballero. Vive al día. Triste o alegre según las circunstancias» [p. 69 -71-].

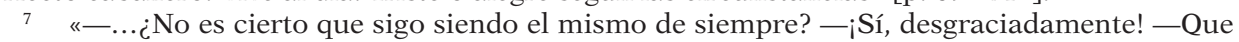
esa desgracia dure otros cuarenta años. Reirá mejor quien ría el último» [p. 163-196-]. Y aquí se acaba la obra.

8 O simplemente, como apunta Launay, la explicaciones de «sentido común» que sensatamente consideran que el camino del sobrino de Rameau es equivocado y que dejando de ser loco se gana mucho más de lo que se pierde (LaunaY, M. «Sur les intentions de Diderot dans le Neveu de Rameau», Diderot Studies, Vol. 8 (1966), pp. 105-119, aquí p. 116). Me recuerda este tipo de explicación a la que ante los movimientos sociales que han surgido desde no hace mucho entre nosotros, de un modo complaciente juzga que eso no sirve para hacer "política», que la voz de la
} 


\subsection{El olvido de la tercera persona, de la objetividad}

Y efectivamente, Rameau muestra como parte de su locura que no hay distancia entre lo que cuenta y él mismo, que Él es lo que cuenta, que no organiza ni domina las palabras sino que la narración le construye (y que no hay sobrino de Rameau en el silencio, sin las palabras donde se muestra a los demás y a sí mismo). Es un «ello» que nunca está presente si no es en el cuento que le cuenta. No hay aquí posibilidad de una identidad relatada en tercera persona ya que el sobrino de Rameau utiliza una gramática que exige la identificación de Él con el relato, que supone que no hay un «yo» que cuenta, domina y maneja el lenguaje, sino que somos en tanto decimos y nos decimos (aunque no necesariamente somos dichos). Por no ser innecesariamente metafísicos vayamos al texto. Entre las pp. 89 y 91 (94 y 99 en la paginación de las Oeuvres Complétes) Él comienza tarareando un allegro para dar allí mismo un concierto de violín que Diderot describe sin dar crédito a lo que está viendo: Rameau se para a fin de afinar las cuerdas, se extasía con algunas notas, se agita "con las mismas convulsiones» que en un concierto real y «lo que resultaba más curioso es que de vez en cuando tanteaba, se corregía como si hubiese cometido un error, y se irritaba de no dominar la pieza con los dedos» [p. 91 -99-]. Este pasaje se repite en todo el libro —si bien con otras descripciones y temas- y, en definitiva, tal es el libro: la continua extrañeza de Diderot ante alguien incapaz de distanciarse de lo que cuenta. Rameau es el relato y por ello es también el fracaso del mecanismo de la tercera persona: no siente como lo otro, es lo otro que se cuenta, no se pone en el lugar del otro, se convierte en esotro. Desde la perspectiva de Rameau no hay modo de considerarse más allá de lo que ahora mismo soy y, por ende, no hay modo de mirarse de manera imparcial, alejado de las circunstancias, del momento y del lugar. Es imposible imaginarnos como si fuéramos otro; simplemente lo somos; pero no de manera contrafáctica o condicional, no de forma imaginativa, sino constitutiva. Por eso la pantomima, la payasada continua es lo que es Él; cuando tiene que decir que alguien estornuda, se convierte en el estornudo mismo y atruena el relato, cuando tiene que imitar los platos que se caen, él mismo se rompe por el suelo... Sí, Rameau es tan payaso como loco y su manera de hablar es la pantomima que le hace deshacerse en lo que cuenta, no dominarlo, sino ser eso que cuenta. Como si la historia (de su vida personal, pero también de su vida con los demás) no se pudiera relatar, sino que hubiera que vivirla o al menos presentarla como algo vivido — vívido— ${ }^{10}$.

Como comenté anteriormente, creo que Benjamin tenía cierta razón cuando estableció que el narrador debe «vivir» el relato pues tan sólo de semejante forma

calle o de los indignados es como la del sobrino de Rameau, falta de consciencia, de sensatez, de la profesión efectiva del político, inconsciente, inconsecuente, absurda en definitiva.

9 Cristina Lara Otxoteke señala convincentemente que las pantomimas son realmente payasadas y creo que eso es algo que no se debe olvidar (Cfr. LARA Otхотеке, C., Diderot como lugar de encuentro, Tesis doctoral leída en la Universidad del País Vasco, 2001, p. 217 y ss.).

10 El mundo del sobrino de Rameau son todos los papeles desplegados por un solo hombre; no unificados o comprendidos o subsumidos por una persona, sino puestos sobre la mesa por un único jugador, como si él mismo tuviera todas las cartas. Y ello es tan imposible que, como señala Fabre en su edición de Le neveu (Ginebra, Droz, 1977), supone al final una pantomima. Esa es la marca de la sátira que Diderot escribe, la mezcla de pantomima y discurso [Cfr. Pounllouv, J.-Y., «Les pantomimes» en M. Duchet \& M. Launay (eds.), Entretiens sur Le neveu de Rameau, Nizet, Paris, 1967, p. 89 y ss.] 
el relato adquiere verosimilitud y alguna garantía de verdad. El narrador no puede contar su narración como si le fuera ajena, como si la viviera en tercera persona. Por el contrario, aun no estando él en el relato contado, no lo presenta de una forma desprendida, sino que quien le oye le exige - como garantía de verdad- que lo viva, que él sea el relato (al menos mientras lo cuenta). Si ello es así, la tercera persona capaz de ponerse en el lugar de los demás, pero no verse afectado íntimamente por ellos, queda fuera de lugar en la economía organizativa de la narración. Eso es también lo que acontece en el caso del sobrino de Rameau, quien es incapaz de no expresar con toda su vida aquello que cuenta. Si Él es la narración ¿cómo no sentirse afectado — compuesto, configurado_ por la misma? No, Él realmente no puede imaginar su vida más allá del relato que presenta ${ }^{11}$; Diderot mismo lo expresa en varias ocasiones cuando afirma que Rameau «interpretaba» y con ello se componía a sí mismo. E interpretar significa generalmente hacer el payaso.

\subsection{La vida que desborda cualquier Biografía -o Historia-}

Pero no es sólo lo que el recuerdo a Benjamín y la economía del relato debe recordarnos, es sobre todo el hecho de que el relato se diga aquí y ahora. Así es el relato y la vida de Rameau: una vida (y un relato) que se establecen «en tiempo real», donde la preocupación es simplemente por relatar lo que acontece y prefiere considerar que todos los sucesos deben ser relatados no porque le cuenten en toda su extensión (auto)biográfica, sino porque «Él es en todo lo que (le) pasa». En buena medida, el sobrino de Rameau no tiene más que presente; no faltan los objetivos futuros - poder desplumar a alguien, inventar algo para dormir caliente, etc.- - eso sí que es innegable, pero es bien seguro que cuando Él haya llevado a cabo su objetivo buscará nuevas actividades, nuevas aventuras, nuevas locuras en una especie de repetición insaciable donde todos los tiempos parecen superponerse sin ningún orden, sin ningún presente ni pasado que nos permita distinguir una identidad capaz de reconocerse a sí misma (y de ser reconocida responsablemente). Podríamos concluir que no hay una Historia de Él, puesto que es incapaz de construir una Biografía, aunque sí que aparecen y desaparecen historias que dicen constantemente al sobrino de Rameau y que le ofrecen mil caminos para poder hacerse, para poder contarse, para poder reconocerse en definitiva. Con ello lo que «Diderot» nos plantea es la posibilidad de que el reconocimiento de sí no sea algo que se da de una vez para siempre, sino que se ha de renovar cada mañana cuando nos miramos al espejo ${ }^{12}$. Es cansado, es

11 «Y, para que pudiera hacerme una idea justa de la fuerza de su víscera, empezó a toser con una violencia capaz de hacer temblar los cristales del café y suspender la atención de los jugadores de ajedrez» [p. 110 -125-]. No, no le vale al sobrino de Rameau simplemente decir que tiene buenos pulmones, debe poner lo que dice a las claras, vivirlo. Ello le parece a Diderot más que inconveniente para vivir en nuestro mundo (por el momento rompe las tazas del café con el consiguiente enfado del dueño e interrumpe las tranquilas partidas de ajedrez que allí tenían lugar), pero Rameau no puede imaginar otro mundo.

${ }_{12}$ No es este lugar para dar muchas vueltas al hecho de que el sobrino de Rameau es su cuerpo, pero creo que merece la pena no olvidar que Él interpreta con su cuerpo, dice con su cuerpo, con sus espasmos, con sus saltos, etc. Por ello parece loco, porque es razón y una cordura que a Diderot le asombra al mismo tiempo que es un cuerpo descontrolado que a Yo le desagrada 
cierto, pero creo que ello apunta a un lugar donde se abren alternativas a nuestro presente. Alternativas estúpidas, poco operativas, posiblemente absurdas, pero ¿acaso se ha mostrado menos absurdo Yo? ${ }^{13}$.

Con una conversación que nunca llega a ser diá-logo no se resuelve nada; como dije todo queda como empezó y más bien la sensación del lector es asistir a una multitud de conversaciones donde ninguna gana. Como se ha apuntado hace tiempo la sátira de Diderot es un diálogo que ha de quedar en tablas ${ }^{14}$. Por ello no debemos pensar en ningún paso ulterior: no vale aquí ni la lectura sensata, ni la que considera que Él es simplemente la búsqueda egocéntrica de placer que ha de ser dominada para poder vivir con los demás, ni la que toma al relato completo como un paso crítico que debe ser solventado a través de una razón ulterior que le comprenda y dé solución. Realmente lo que se lee en esta obrita es una charla que, como toda charla no deja de ser un deambular continuo, un viaje que no sabe nunca por donde va a terminar caminando. No hay nada solucionado, no tenemos la última palabra y más bien estamos buscando continuamente la primera palabra con la que volver a comenzar una conversación que efectivamente nada dice aun cuando realmente no pare de decir cosas. Se ha dicho que Diderot es un maestro del diálogo (yo preferiría decir de la conversación) y ello se ve en que da una fuerza igual a los antagonistas: no está nunca todo resuelto desde el principio como lo estaría si la lectura hegeliana tuviera razón, o como si la tuviera la cordura que introduce a Él como una pulsión que ha de ser dominada para poder vivir con calma, paz y tranquilidad ${ }^{15}$; por el contrario la no conclusión es vital para entender una vida - un mundo - donde el fundamento es la apertura a lo diferente, al otro que nos sorprende y confunde, a la posibilidad de reconocernos de nueva manera un buen día por la mañana. Pero el cambio, la variación que ha de residir dentro de la sustancia de nuestras convicciones más estables (de nuestras concepción de nosotros mismos y del mundo que consideramos digno de ser vivido), no significa irracionalidad despreciable; como el mismo Diderot dice en una carta a Sophie Volland, en la conversación todo aparece con algún tipo de unión pues ni siquiera en la cabeza del loco las cosas están descosidas ${ }^{16}$. Efectivamente, lo absurdo nunca es tan irracional como se nos ha hecho creer desde una Historia que no desea otro presente; y si deseamos proponer algo diferente para nuestra vida, si deseamos

pues la acumulación de movimientos sin unión interna produce un ser desposeído de sí (HoBson, M., «Pantomime, spasme et parataxe: Le neveu de Rameau», Revue de Métaphysique et Morale, 89, 2 (1984), pp. 197-213, aquí p. 209), como si en sus pantomimas, los gestos sucediéndose sin coordinación aparente, pusieran en claro que lo voluntario y lo involuntario, la razón y el cuerpo, no se diferenciaran. Casi como si fueran tan importantes las historias sin coordinación aparente como la gran Historia capaz de coordinar cualquier cosa.

13 Apunta Crocker que el sobrino de Rameau es un nihilista ligado al sentimiento del absurdo: «Él se enfrenta a la grandeza mediante una interpretación lunática, de clown. Esta interpretación no solamente está desprovista de la dignidad y el valor moral, sino que además al incorporar el absurdo como su propia esencia, señala lo absurdo de nuestros valores, de nuestros actos, de nuestra existencia» (CROCKer, L. G., «Le neveu de Rameau, une experience morale», Cahiers de l'Association International des Études Francaises, no 13 (1961), pp. 133-155, aquí p. 138).

14 Niklaus, R., Reseña del libro de James Doolittle, Rameau's Nephew. A Study of Diderot's Second, en The Modern Language Review, 56. 4 (1961) pp. 615-616).

15 Cfr. Crocker, L. G., art. cit., p. 138.

16 Citado en Launay, M., art. cit., p. 110. 
herramientas críticas y constructivas para poder apechar con nuestro trabajo cotidiano, la única manera de plantear hipótesis explicativas o deseos justificados es a través de una conversación como la que mantienen Yo y Él. Conversación que realmente ni es una ni es nunca un diá-logo; como apunta Judith Spencer, el sobrino de Rameau encuentra su lugar dentro del «desbordamiento del texto que propone una multiplicidad de diálogos: diálogo evidentemente entre Yo y Él; diálogo entre Yo en tanto que narrador y el mismo ("yo me entretengo conmigo mismo"); diálogo entre el mismo autor-bufón en la medida en que Yo y Él representan los dos aspectos de su estar dividido por los cuales él busca llegar a su propia verdad, diálogo entre Él y el mismo (“...él se escuchaba embelesado”); entre Él y todos los personajes imaginarios que son objetos de su imitación» ${ }^{17}$.

Esa es, creo, una buena alternativa a nuestra Historia; ese es el lugar donde infinitas Felisa Viñas aparecen no para ofrecer la justa alternativa, sino para ofrecer alternativas, diferentes recodos en el camino, distintos horizontes divisados (e imaginados). Entender la historia como viaje y no como ir de un sitio a otro, como un viaje de aprendizaje, como ensayo más que como tratado, es lo que el sobrino de Rameau nos ofrece como herramienta crítica para proponer nuestro presente. Mala herramienta se podría pensar si necesita siempre de un Yo que presente el texto, que conduzca y narre, en tercera persona, el encuentro con Él para que nos demos cuenta de lo que este puede ofrecer. Mas quien así pensare erraría pues realmente el texto se deshace cada vez que el sobrino de Rameau habla y Diderot nos confiesa su amor y su odio hacia él sin poder distanciarse para dar un último veredicto. Quizás esa sea la genialidad de Diderot que construye un diálogo con una tercera persona incapaz de dominar el texto, incapaz de no sentir admiración por la locura y muy capaz, por el contrario, de expresar que Él es también Yo sin que eso suponga la necesidad de que Yo le subsuma, o le supere, o le tome en cuenta y sí, tan sólo, el hecho de que se puedan encontrar camino de la Ópera e iniciar una conversación que nunca llegará a entender ni quién es Él ni, me da la impresión, quién es $\mathrm{Yo}^{18}$.

Es como si el uso consciente de la tercera persona terminara por desbordarla pues, efectivamente, Yo y Él hablan, ninguno deja de usar la tercera persona; Él habla de sí mismo en tercera persona no pocas veces, pero puesto que es una conversación aparece constantemente como tú y cuando habla en tercera persona lo hace a un público que resulta ser él mismo; Yo habla de la situación en primera persona, pero también desdoblándose en un narrador que nunca es omnicomprensivo pues cuenta incluso lo que no entiende (y con ello deja habar a Él sin que exista una posición desde la que se vean las cosas bien claras) ${ }^{19}$. Funciona

17 Spencer, J., «Dislocation existentielle et désarticulation esthétique dans Le Neveu de Rameau», Revue Romane, 31, 2 (1996), 257-26; aquí p. 262-3.

18 Es evidente que Él está loco y hace cosas absurdas, pero no deja de ser una persona íntegra y admirada por Diderot. ¿Integro alguien que se precia de hipócrita para engañar a quien le puede dar de comer? Si soy sincero, no sé de qué tipo de integridad se puede hablar aquí, pero es evidente que existe una integridad fundamental que se sobrepone a las contradicciones (L. G. CROCKER, art. cit., p. 143) y en buena medida por ello Diderot le admira, le ama tanto como le odia, le sabe parte de sí.

19 Este juego de personas narrativas es lo que Y. Sumi utiliza para dar cuerpo a su tesis sobre Diderot (tan problemática como interesante). Cfr. Yoichi Sumi, Le Neveu de Rameau: Caprices et logiques du jeu, Tokio, Librairie-Éditions France Tosho, 1975. 
aquí la empatía, el dejar aparecer la diferencia incluso cuando no se entiende y resulta desasosegante; lo otro no tiene por qué ser parecido a lo propio siendo simplemente un elemento más que la conversación considera aun sin comprender; y es precisamente esa empatía la que estira tanto la tercera persona que la lleva a desbordar sus límites (limitaciones) iniciales: la historia que se cuenta aquí no está fijada ni en el inicio (por la mirada que se vaya a utilizar) ni en el desarrollo (por el lenguaje que se fuera a usar) ni por supuesto en su final; es más bien una historia que se constituye en maestra que puestos a enseñar prefiere, antes que traer de casa las materias y la Enciclopedia a aprender, mirar a quien la escucha y unirse a su esfuerzo de configuración de la propia identidad. La historia que se cuenta desde esa tercera persona desbordada acompaña el esfuerzo por hacer mundo antes que enseñar cómo ha de ser ese mundo.

\subsection{La identidad, la historia, sin orden}

Sin la distancia de la tercera persona, Él termina no siendo sino el viaje sin orden ni concierto del relato. Sin orden ni concierto pues no consigue constituir una identidad fija y con ello ni siquiera obtiene una individualidad a la que se pueda hacer responsable de sus actos futuros o pasados. Realmente Rameau es un inconsecuente [p. 82 -88-] y eso es lo que más perturba a Diderot y a nosotros mismos, que sospechamos que con la inconsecuencia, con la contradicción irresponsable no hay mundo que se pueda edificar ${ }^{20}$. De hecho lo que a Diderot le confunde, porque no lo entiende, es la contradicción continua de Rameau: «me confundía tanta sagacidad, tanta bajeza; ideas tan justas y tan falsas alternativamente; una ignominia tan completa y una franqueza tan poco corriente» [p. 87 -95-]. Él es un inconsecuente deshecho en los mil relatos que cuenta donde se expone una y otra vez sin ver más salida que el exponerse, pero sin que nunca se halle síntesis, acoplamiento o una posibilidad de reposar en una (auto)biografía definitiva ${ }^{21}$.

Con todo, no es la inconsecuencia algo que Él disfrute pues no pocas veces confiesa que lo pasa mal con su vida, que desearía ser otro, que odia su condición ${ }^{22}$.

20 «Deberíais tomar partido y permanecer firme en vuestra elección» [p. 74 -78-] es repetido en multitud de ocasiones por Yo a lo que la respuesta es siempre la misma: quien no se mira de modo desprendido no puede tener firmeza ninguna.

21 «OH loco, archiloco! —exclamé-, ¿cómo es posible que en tu mala cabeza haya ideas tan justas revueltas con otras tan extravagantes?» [p. $94-104-$ ]. Como Yo hace, también es habitual tomar a Él como un loco, cuando no simplemente como un estúpido o una personalidad alienada (pues nunca es él, sino que es lo que le va pasando) Posiblemente de manera más clásica se le pueda entender como epítome de la conciencia desgarrada tal y como le entendió Hegel; pero traigamos a la cabeza por un momento el modo como aparece este texto ante los adalides de la comprensión hegeliana y juzguemos con calma dónde está la locura, si en el payaso o en quienes con todos los parabienes de la racionalidad consideran que Él en buena medida es el materialismo del XVIII que "ha permitido a la conciencia desgarrada volver a ser en sí, esta pura igualdad con ella misma de la conciencia de sí que llega a ser ella misma» (Mougin, H., «Hegel et le Neveu de Rameau», Europe, vol. 24, 8 (1946), pp. 2-11, aquí p. 10).

${ }^{22}$ El sobrino de Rameau lo confiesa sin ambages: tiene envidia de no ser otro que sí mismo pues es mediocre y eso no le gusta. Y es que quizás el camino que presenta no sea el de la tranquilidad, el de estar a gusto con nosotros mismos, sino el de la continua experimentalidad, el que se impugna continuamente a sí mismo. Es esta la única manera de entender la crítica ínsita en la misma Modernidad. 
Sin embargo, sigue siendo el sobrino de Rameau, sin nombre propio, sin identidad, como si la única vida posible fuera la del que se sabe tan humano que es contingente y frágil hasta la inconsecuencia, hasta deshacerse en el deseo de dejar de ser lo que se es. Así es la vida, nos enseña Diderot en este librito, e intentar perpetuarla en una identidad que se puede contar con una historia fija (fijada y determinada) es sencillamente tratar de engañar a la mayoría de edad que en algún momento se ofreció como esencia de la Modernidad. Realmente no ha de haber miedo ninguno a deshacerse pues es importante decir que, con todo, el sobrino de Rameau no se borra, sino que por el contrario campea durante todo el texto (es él quien lo lleva realmente con sus payasadas y la tercera persona, sea Diderot sea Yo, parece que continuamente corre, admirada y con la lengua fuera detrás de sus locuras intentando dar fe de todas ellas). El tiempo de la vida, de este modo, no es aquello que un gran relato de vida unifica bajo el emblema de una identidad, sino que significa el lugar donde se dice el personaje, donde presenta sus mil fragmentaciones que no pueden ser reunidas por la sencilla razón de que tal reunión necesitaría un punto de apoyo más allá de la propia vida que se relata. Por eso Él no para de hablar; y ello no porque sea un pesado, sino porque sólo hablando se reclama el derecho a hablar (a componer la propia vida). Sin otra palabra que la sucesión de palabras, tan sólo hablando se consigue el derecho a no callar, a decirse en todos lados. Bien que de modo frágil, bien que sin someterse a una gran necesidad, orden u organización, pero constituyéndose siempre como este que soy aquí y ahora. Esa vida que no es capaz de consagrar una vida, sino que es una ebullición de palabras para contar en tiempo real lo que alguna vez aconteció, obliga a que toda reclamación sea precisamente la del derecho a no callar. Y decir cualquier cosa.

¡Cualquier cosa!¡Cuán poca responsabilidad! Aunque no nos estaría de más repensar lo que entendemos por responsabilidad. O incluso volver a pensar qué papel debemos dar al responsable pues dar cuenta y razón de lo que se hace, como el sobrino de Rameau, no deja de ser un acto tremendamente responsable (y quizás toda la responsabilidad que a los humanos nos compete). Todos en nuestra primera lectura de El sobrino de Rameau hemos pensado que la posición de Él es «intelectualmente insostenible y esencialmente ridícula pues el pobre diablo no saca más beneficio del vicio que de la música» ${ }^{23}$, pero ¿hemos sacado gran beneficio de interpretaciones intelectualmente sostenibles? No en demasía podrían responder aquellos, creo que muchos, que no se han beneficiado nunca de ellas y que son quienes han quedado condenados al desierto de la irracionalidad, la locura y la inconsecuencia.

\section{3. ¿LOCURA COMO CRÍTICA?}

La falta de una identidad segura y estable del sobrino de Rameau, es el ejemplo que deseo recoger para imaginar una historia crítica, una historia que fuera capaz de saltar el espacio mismo de composición histórica que usamos hoy

23 Chapiro, F. \& GoldzinK, J., «Le Neveu de Rameau, après Michel Foucault», Raisons politiques, 17 (2005), pp. 161-177, aquí pp. 170-1. 
y que apostara por huir de la inteligencia y la cordura (cuando estas se expresan, como en nuestra Historia, remitiéndose a la unión entre pasado, presente y futuro y desde la perspectiva de un universalismo pleno de objetividad o cientificidad o racionalidad). En la inconsistente charla entre Diderot y su interlocutor (en la que Yo se ve también a sí mismo sin necesidad de reconocerse en Él) es donde podemos recoger un modo de historia que nos podría ser útil para cosechar un presente diferente. Desgajado, pudiera ser, de cualquier pasado que hasta ahora nos hayan presentado; receloso, pudiera ser, de cualquier esperanza que hasta ahora se nos haya dibujado. Una historia que rompiera con el continuo histórico (tan ficticio como optado) pues se haría tan sólo desde un presente que, loco, ni siquiera sería consciente de sí y debiera inventarse a cada momento, a cada interés; un presente que sería tan presente que no sino momentos sería; un presente tan intrascendente, tan presente, que tan sólo se miraría a sí para considerar en sus necesidades actuales el origen de sus esperanzas y deseos (y sabiendo que mirarse a sí, siendo un presente desgarrado, no es sino mirar a todo lo que se puede ser incluso sin entender cómo se puede ser semejante cosa).

De tal presente partiría una historia crítica que nunca se escribiría con mayúsculas y por ello permitiría la proliferación de historias, por pequeñas, locas e intrascendentes que pudieran parecer. De este modo, creo, podríamos mirar y aprender, como curiosos, de estos movimientos sociales que a duras penas afloran a nuestro derredor hoy, sin creer que ya teníamos en nosotros su significado y objetivo, sus esperanzas; sin creer que se plantean en el mismo campo de juego donde habitualmente hasta ahora mismo han jugado nuestras preocupaciones sociales y políticas. Entenderlos como algo no imaginado es poder aprender —más que reconocer fuera de nosotros lo que siempre nos ha compuesto-; y entenderlos de tal manera es también aceptar que al cabo en nosotros no tenemos nada más que modos diferentes de tener esperanza (modos diferentes de presentar nuestra lucha por ser felices). Y es bueno considerar que ni siquiera un nombre tenemos pues cuando nos podamos nombrar con un nombre corremos el peligro de creer que ese puede ser el nombre que nos nombre para siempre.

Universidad de Alcalá

Julio Seoane Pinilla

julio.seoane@uah.es

[Artículo aprobado para publicación en diciembre de 2015] 